\title{
Targeted temperature management for survivors of sudden cardiac arrest
}

\author{
Alex M. Parker, Matthew F. Gottbrecht and Lawrence W. Gimple* \\ Department of Clinical Cardiology, University of Virginia Health System, USA
}

\section{Background}

It is estimated that over 300,000 people each year with suffer from Sudden Cardiac Arrest (SCA) in the United States [1]. SCA frequently leads to prolonged hospitalization and is highly fatal with a mortality rate of approximately $90 \%$. The leading cause of morbidity and mortality in SCA is profound neurologic injury, primarily due to lack of cerebral circulation during the arrest period, followed by secondary insults such as cerebral edema, reperfusion injury and hyperthermia [2]. SCA most commonly occurs outside of the hospital where mortality is significantly worse than in patients who suffer SCA inside a hospital $[1,3]$. SCA is often further stratified by presenting rhythm that can be "shockable" (treated with an electrical defibrillation such as Ventricular Tachycardia (VT) / Ventricular Fibrillation (VF)) versus rhythms not treated with defibrillation such as pulseless electrical activity (PEA) or asystole.

Since the landmark trials of Treatment of comatose survivors of out of hospital cardiac arrest with induced hypothermia [4] and the hypothermia after cardiac arrest study group [5], TTM has become a standard of care for Out of Hospital Cardiac Arrest (OHCA) survivors who are comatose. Although initial trials only demonstrated a benefit of TTM after VF / VT arrest, the practice has been expanded to nearly all patients due to the improvement in neurologic outcomes and survival [6-8].

In December 2013 Nielsen et al. published the Targeted Temperature Management $33^{\circ} \mathrm{C}$ versus $36^{\circ} \mathrm{C}$ after cardiac arrest [9] trial which resulted in an increased focus on maintaining normothermia after cardiac arrest and led to the currently preferred term "Targeted Temperature Management" (TTM) over mild therapeutic hypothermia. At this time cooling to a target temperature of $32^{\circ} \mathrm{C}$ to $34^{\circ} \mathrm{C}$ is still standard of care in comatose survivors of OHCA, though adoption rates vary between institutions [10].

\section{Treating patients with temperature management}

In 2002 The International Liaison Committee on Resuscitation (ILCOR) released an advisory statement stating, "Unconscious adult patients with spontaneous circulation after out-of-hospital cardiac arrest should be cooled to $32^{\circ} \mathrm{C}$ to $34^{\circ} \mathrm{C}$ for 12 to 24 hours when the initial rhythm was Ventricular Fibrillation (VF) and noting that such cooling may also be beneficial for other rhythms or in-hospital cardiac arrest" [11]. Since then the American Heart Association guidelines has also incorporated recommendations for temperature management for survivors of SCA with non-shockable rhythms [12].

The decision to initiate TTM in comatose survivors of SCA should be made quickly as evidence suggests that mortality increases with each hour of treatment delay [13]. Cold saline can be safely infused rapidly and can be made available in emergency response vehicles [14], however caution should be used when infusing cold saline in patients who have not achieved ROSC or are hemodynamically unstable given the findings of the RINSE trial, in which cold saline infusion prior to ROSC appeared to be associated with a decreased rate of ROSC in patients with VT/VF but overall had no impact on outcomes [15].

Targeted temperature management can be achieved with conventional methods or with modern commercial cooling devices [16]. Conventional methods often include an initial bolus of $4^{\circ} \mathrm{C}$ saline followed by the placement of ice bags to the neck, groin and axilla or the use of rubber cooling blankets. These methods, while having the benefit of being widely available and quick to initiate, lack the internal feedback of intravascular cooling and are less effective in maintaining the targeted temperature $[17,18]$. There are commercially available surface cooling devices such as Arctic Sun device (Medivance) and others. These systems have internal feedback to avoid overcooling and seem to be more efficient at reaching targeted temperatures [19].

Intravascular cooling is able to rapidly achieve targeted temperature and may reduce the time out of the targeted range better than surface cooling techniques [19]. These systems use a closed circuit of cooled fluid that circulates past venous blood. The primary complications associated with these devices are similar to other central lines and are related to vessel injury, venous thrombosis and catheter related bloodstream infection [20,21]. In general, however, these catheters appear to be safe when inserted by experienced intensivists.

In 2015 Deye et al. published a randomized control trial comparing endovascular and external temperature management [17]. In this study 400 survivors of SCA were randomly assigned to the Coolgard (Zoll) catheter or external cooling using fans, ice packs to the torso, groin and head, and a tent. There was no identifiable difference in neurologic recovery, however the group receiving endovascular TTM more rapidly achieved and maintained the targeted temperature $\left(33^{\circ} \mathrm{C}\right)$.

\section{Prognosis}

Despite advances in post cardiac arrest care, a resuscitated cardiac arrest survivor still has a very poor prognosis. One of the most challenging aspects in caring for SCA survivors who are treated with TTM is estimating the specific prognosis of the individual patient. Determination of prognosis is typically deferred for 72 hours after a

Correspondence to: Lawrence W. Gimple, Department of Clinical Cardiology, University of Virginia Health System, POBox 800158, Charlottesville, VA 22908 USA, Tel: 434924 9591; E-mail. lgimple@virginia.edu

Received: July 05, 2017; Accepted: July 25, 2017; Published: July 27, 2017 
hypoxic ischemic event and is often based primarily on physical exam [22]. The implementation of temperature management, however frequently requires the use of sedatives and paralytics to reduce shivering, thus limiting the ability to determine prognosis by physical examination alone [23].

In 2010 Rossetti et al. studied 111 patients after cardiac arrest that were treated with TTM and observed that at 72 hours after the arrest patients were more likely to have false negative predictors of poor prognosis such as incomplete brainstem reflexes, myoclonus, and especially absent pain responses [24]. Somatosensory Evoked Potentials and EEG may be useful tools in determining a prognosis in comatose patients, yet these methods have their limitations as well [25]. Patients generally must be free from all sedating and neuromuscular blocking agents prior to attempting prognostication.

It can be difficult to clinically ascertain which patients will benefit from temperature management prior to initiating treatment. Since the adoption of TTM after SCA, attempts have been made to determine early in the patient's course the likelihood of an individual surviving with good neurologic recovery. Reduced time from activation of emergency services to spontaneous circulation is strongly associated with better neurologic outcomes presumably due decreased time without cerebral perfusion [26]. Clinical models have been developed following flow diagrams using patient specific characteristics including time to ROSC to predict outcomes [27]. Unfortunately it is common that the exact time that an individual became pulseless cannot be determined.

A recently published scoring system by Kiehl et al. called C-GRApH enables the clinician to stratify the likelihood of poor neurologic outcome based on 5 equally weighted variables which are quantitative and typically known at the time of initial hospital evaluation [28]. In this scoring system the patient receives one point for each of the following: known history of (C)AD at the time or presentation, serum (G)lucose $\geq 200 \mathrm{mg} / \mathrm{dL}$, (R)hythm of arrest other than VT/VF, (A)ge $>45$, and $(\mathrm{pH}) \leq 7.0$. Higher scores indicate increased likelihood of poor neurologic outcomes. This scoring system focuses on variables that are available at the time of admission to the hospital, such as rapidly available labs, and does not rely on time of the arrest or ROSC.

\section{Economic cost of medical care after SCA}

Data on the economic costs of medical care associated with SCA is limited and largely from before the advent of TTM [29-32]. In the era of TTM and early percutaneous coronary intervention in postSCA patients with favorable resuscitation features [33], economic (and emotional) costs have almost certainly increased. One more recent single-center study conducted in the United Kingdom of 69 patients admitted for OHCA reported an approximate cost per survivor to discharge, which accounts for the total cost of survivors and nonsurvivors, of $£ 50,000$. The cost per survivor with a Cerebral Performance Score of 1-2 (indicating good neurologic outcome) was $£ 65,000$ with an estimated cost per quality of life year (QALY) of $£ 16,000,69 \%$ of these costs were related to intensive care [34].

\section{Summary}

Sudden cardiac arrest is a common, unfortunate, and highly fatal event which is often associated with poor neurologic recovery. SCA is associated with significant emotional and economic burdens on families. TTM is an effective treatment that improves neurologic outcomes in selected patients. Determining prognosis in SCA can be challenging in the era of TTM, however novel models and diagnostic tools may aid in the early stratification of comatose patients.

\section{References}

1. Benjamin EJ, Blaha MJ, Chiuve SE, Cushman M, Das SR, Deo R, et al. (2017) Heart Disease and Stroke Statistics-2017 Update: A Report From the American Heart Association. Circulation 135: e146-e603. [Crossref]

2. Sekhon MS, Ainslie PN, Griesdale DE (2017) Clinical pathophysiology of hypoxic ischemic brain injury after cardiac arrest: a "two-hit" model. Crit Care 21: 90. [Crossref]

3. Nolan JP, Soar J, Smith GB, Gwinnutt C, Parrott F, et al. (2014) Incidence and outcome of in-hospital cardiac arrest in the United Kingdom National Cardiac Arrest Audit. Resuscitation 85: 987-992. [Crossref]

4. Bernard SA, Gray TW, Buist MD, Jones BM, Silvester W, et al. (2002) Treatment of comatose survivors of out-of-hospital cardiac arrest with induced hypothermia. $N$ Engl $J$ Med 346: 557-563. [Crossref]

5. Hypothermia after Cardiac Arrest Study Group (2002) Mild therapeutic hypothermia to improve the neurologic outcome after cardiac arrest. N Engl J Med 346: 549-556. [Crossref]

6. Dumas F, Grimaldi D, Zuber B, Fichet J, Charpentier J, et al. (2011) Is hypothermia after cardiac arrest effective in both shockable and nonshockable patients?: insights from a large registry. Circulation 123: 877-886. [Crossref]

7. Testori C, Sterz F, Behringer W, Haugk M, Uray T, et al. (2011) Mild therapeutic hypothermia is associated with favourable outcome in patients after cardiac arrest with non-shockable rhythms. Resuscitation 82: 1162-1167. [Crossref]

8. Vaahersalo J, Hiltunen P, Tiainen M, Oksanen T, Kaukonen KM, et al. (2013) Therapeutic hypothermia after out-of-hospital cardiac arrest in Finnish intensive care units: the FINNRESUSCI study. Intensive Care Med 39: 826-837. [Crossref]

9. Nielsen N, Wetterslev J, Cronberg T, Erlinge D, Gasche Y, et al. (2013) Targeted temperature management at $33^{\circ} \mathrm{C}$ versus $36^{\circ} \mathrm{C}$ after cardiac arrest. $N$ Engl J Med 369: 2197-2206. [Crossref]

10. Stub D, Schmicker RH, Anderson ML, Callaway CW, Daya MR, et al. (2015) Association between hospital post-resuscitative performance and clinical outcomes after out-of-hospital cardiac arrest. Resuscitation 92: 45-52. [Crossref]

11. Nolan JP, Morley PT, Vanden Hoek TL, Hickey RW, Kloeck WG, et al. (2003) Therapeutic hypothermia after cardiac arrest: an advisory statement by the advanced life support task force of the International Liaison Committee on Resuscitation. Circulation 108: 118-121. [Crossref]

12. Neumar RW, Shuster M, Callaway CW, Gent LM, Atkins DL, et al. (2015) Part 1: Executive Summary: 2015 American Heart Association Guidelines Update for Cardiopulmonary Resuscitation and Emergency Cardiovascular Care. Circulation 132(Suppl 2) S315-367. [Crossref]

13. Mooney MR, Unger BT, Boland LL, Burke MN, Kebed KY, et al. (2011) Therapeutic hypothermia after out-of-hospital cardiac arrest: evaluation of a regional system to increase access to cooling, Circulation 124: 206-214. [Crossref]

14. Li H, Li Y, He W, Wang Z (2014) [Efficacy and safety of early rapid infusion of icy normal saline in patients after cardiopulmonary resuscitation]. Zhonghua Wei Zhong Bing Ji Jiu Yi Xue 26: 710-713. [Crossref]

15. Bernard SA, Smith K, Finn J, Hein C, Grantham H, et al. (2016) Induction of Therapeutic Hypothermia During Out-of-Hospital Cardiac Arrest Using a Rapid Infusion of Cold Saline: The RINSE Trial (Rapid Infusion of Cold Normal Saline). Circulation 134: 797-805. [Crossref]

16. Seder DB, Van der Kloot TE (2009) Methods of cooling: practical aspects of therapeutic temperature management. Crit Care Med 37(7 Suppl) S211-222. [Crossref]

17. Deye N, Cariou A, Girardie P, Pichon N, Megarbane B (2015) Endovascular Versus External Targeted Temperature Management for Patients With Out-of-Hospital Cardiac Arrest: A Randomized, Controlled Study. Circulation 132: 182-193. [Crossref]

18. Merchant RM, Abella BS, Peberdy MA, Soar J, Ong ME, et al. (2006) Therapeutic hypothermia after cardiac arrest: unintentional overcooling is common using ice packs and conventional cooling blankets. Crit Care Med 34(12 Suppl): S490-494. [Crossref]

19. Hoedemaekers CW, Ezzahti M, Gerritsen A, van der Hoeven JG (2007) Comparison of cooling methods to induce and maintain normo- and hypothermia in intensive care unit patients: a prospective intervention study. Crit Care 11: R91. [Crossref]

20. Simosa HF, Petersen DJ, Agarwal SK, Burke PA, Hirsch EF (2007) Increased risk of deep venous thrombosis with endovascular cooling in patients with traumatic head injury. Am Surg 73: 461-464. [Crossref] 
21. Schmutzhard E, Engelhardt K, Beer R, Brössner G, Pfausler B, et al. (2002) Safety and efficacy of a novel intravascular cooling device to control body temperature in neurologic intensive care patients: a prospective pilot study. Crit Care Med 30: 24812488. [Crossref]

22. Levy DE, Caronna JJ, Singer BH, Lapinski RH, Frydman H, et al. (1985) Predicting outcome from hypoxic-ischemic coma. JAMA 253: 1420-1426. [Crossref]

23. Taccone F, Cronberg T, Friberg H, Greer D, Horn J, et al. (2014) How to assess prognosis after cardiac arrest and therapeutic hypothermia. Crit Care 18: 202. [Crossref]

24. Rossetti AO1, Oddo M, Logroscino G, Kaplan PW (2010) Prognostication after cardiac arrest and hypothermia: a prospective study. Ann Neurol 67: 301-307. [Crossref]

25. Paolo Zanatta, Federico Linassi, Anna Paola Mazzarolo, Maria Arico, Enrico Bosco, et al. (2015) Pain-related Somato Sensory Evoked Potentials: a potential new tool to improve the prognostic prediction of coma after cardiac arrest. Crit Care 19: 403. [Crossref]

26. Komatsu T, Kinoshita K, Sakurai A, Moriya T, Yamaguchi J, et al. (2014) Shorter time until return of spontaneous circulation is the only independent factor for a good neurological outcome in patients with postcardiac arrest syndrome. Emerg Med J 31: 549-555. [Crossref]

27. Goto Y, Maeda T, Goto Y (2013) Decision-tree model for predicting outcomes after out-of-hospital cardiac arrest in the emergency department. Crit Care 17: R133. [Crossref]
28. Kiehl EL, Parker AM, Matar RM, Gottbrecht MF, Johansen MC, et al. (2017) C-GRApH: A Validated Scoring System for Early Stratification of Neurologic Outcome After Out-of-Hospital Cardiac Arrest Treated With Targeted Temperature Management. J Am Heart Assoc 6. [Crossref]

29. Naess AC, Steen PA (2004) Long term survival and costs per life year gained after outof-hospital cardiac arrest. Resuscitation 60: 57-64. [Crossref]

30. Anouk P. van Alem, Marcel G.W. Dijkgraaf, Jan G.P. Tijssen, Rudolph W. Koster (2004) Health system costs of out-of-hospital cardiac arrest in relation to time to shock. Circulation 110: 1967-73.

31. Graf J, Muhlhoff C, Doig GS, Reinartz S, Bode K, et al. (2008) Health care costs, longterm survival, and quality of life following intensive care unit admission after cardiac arrest. Crit Care 12: R92. [Crossref]

32. Swor R, Lucia V, McQueen K, Compton S (2010) Hospital costs and revenue are similar for resuscitated out-of-hospital cardiac arrest and ST-segment acute myocardial infarction patients. Acad Emerg Med 17: 612-616. [Crossref]

33. Rab T, Kern KB, Tamis-Holland JE, Henry TD, McDaniel M, et al. (2015) Interventional Council, Cardiac Arrest: A Treatment Algorithm for Emergent Invasive Cardiac Procedures in the Resuscitated Comatose Patient. J Am Coll Cardiol 66: 6273. [Crossref]

34. Petrie J, Easton S, Naik V, Lockie C, Brett SJ, et al (2015) Hospital costs of out-of hospital cardiac arrest patients treated in intensive care; a single centre evaluation using the national tariff-based system. BMJ Open 5: e005797. [Crossref]

Copyright: (C2017 Parker AM. This is an open-access article distributed under the terms of the Creative Commons Attribution License, which permits unrestricted use, distribution, and reproduction in any medium, provided the original author and source are credited. 